\title{
Middle Eastern or North African
}

National Cancer Institute

\section{Source}

National Cancer Institute. Middle Eastern or North African. NCI Thesaurus. Code C43866.

Denotes a person from any of the countries of southwest Asia and northeastern Africa; this region includes those countries east of Egypt and south of T urkey and extending to Iran in the east. 